\title{
Hydrogenation of alkynyl substituted aromatics over rhodium/silica
}

\author{
Joseph W. Gregory ${ }^{1}\left[\right.$ [ $\cdot$ S. David Jackson ${ }^{1}$ (i)
}

Received: 16 July 2021 / Accepted: 22 July 2021 / Published online: 4 August 2021

(c) The Author(s) 2021

\begin{abstract}
The cascade reactions of phenylacetylene to ethylcyclohexane and 1-phenyl-1-propyne to propylcyclohexane were studied individually, under deuterium and competitively at $343 \mathrm{~K}$ and 3 barg pressure over a $\mathrm{Rh} /$ silica catalyst. Both systems gave similar activation energies for alkyne hydrogenation $\left(56 \pm 4 \mathrm{~kJ} \mathrm{~mol}^{-1}\right.$ for phenylacetylene and $50 \pm 4 \mathrm{~kJ} \mathrm{~mol}^{-1}$ for 1-phenyl-1-propyne). Over fresh catalyst the order of reactivity was styrene $>$ phenylacetylene $\gg$ ethylbenzene. Whereas with the cascade hydrogenation starting with phenylacetylene, styrene hydrogenated much slower phenylacetylene even once all the phenylacetylene was hydrogenated. The activity of ethylbenzene was also reduced in the cascade reaction and after styrene hydrogenation. These reductions in rate were likely due to carbon laydown from phenylacetylene and styrene. Similar behavior was observed with the 1-phenyl-1-propyne cascade. Deuterium experiments revealed similar positive KIEs for phenylacetylene (2.6) and 1-phenyl-1-propyne (2.1). Ethylbenzene hydrogenation/deuteration gave a KIE of 1.6 obtained after styrene hydrogenation in contrast to the inverse KIE of 0.4 found with ethylbenzene hydrogenation/deuteration over a fresh catalyst, indicating a change in rate determining step. Competitive hydrogenation between phenylacetylene and styrene reduced the rate of phenylacetylene hydrogenation but increased selectivity to ethylbenzene suggesting a change in the flux of sub-surface hydrogen. In the competitive reaction between 1-phenyl-1-propyne and propylbenzene, the rate of hydrogenation of 1-phenyl-1-propyne was increased and the rate of alkene isomerization was decreased, likely due to an increase in the hydrogen flux for hydrogenation and a decrease in the hydrogen species active in methylstyrene isomerization.
\end{abstract}

Keywords Phenylacetylene $\cdot 1$-phenyl-1-propyne $\cdot$ Hydrogenation $\cdot$ Rh/silica

S. David Jackson

David.Jackson@glasgow.ac.uk

1 Centre for Catalysis Research, School of Chemistry, University of Glasgow, Glasgow G12 8QQ,

Scotland, UK 


\section{Introduction}

Hydrogenation of alkynes has been investigated for almost 150 years [1] but it was not until the middle of last century that detailed analysis of catalysts and products was possible [2, 3]. Research has continued and over the last 15 years considerable advances have been made in our understanding of aliphatic alkyne and alkene hydrogenation over palladium [4-7] and aliphatic alkene hydrogenation and isomerization over platinum systems [8, 9]. Aromatic alkyne hydrogenation historically has had much less attention but over recent years the number of publications has increased [10-14]. However, reactions where there is competition have had very little attention [15-19]. Similarly, much of our new understanding relates to reactions over palladium and to a lesser extent platinum. The role of surface and sub-surface hydrogen, carbon and particle size and shape effects have all been delineated for palladium but not for other metals. Other metals such as rhodium have shown some indications that their behavior pattern was similar to palladium [20] but detailed studies have not yet been undertaken. In contrast to the increase in understanding for alkyne hydrogenation, at least over palladium, aromatic hydrogenation is much less well understood [4].

In this study we were interested in examining the hydrogenation of alkynyl aromatics. The reaction of species such as phenylacetylene and 1-phenyl-1-propyne is usually studied from the alkyne hydrogenation point of view $[12,21]$. However, the systems are considerably more complex, consider in a batch reactor as the alkyne is converted to alkene after $50 \%$ conversion there is typically more alkene present than alkyne and the reaction can be considered competitive between the alkyne and alkene. At the same time there is the potential for hydrogenation of the aromatic ring. This is not usually considered, as ring hydrogenation is much slower than alkyne hydrogenation [4]. This is a fair consideration over palladium catalysts as palladium is a poor aromatic hydrogenation catalyst [22]. However, rhodium is the most active metal for ring hydrogenation and in previous work we examined the hydrogenation of alkyl aromatics to substituted cyclohexanes over a rhodium catalyst [23]. The competitive hydrogenation between toluene, ethylbenzene and propylbenzene revealed that propylbenzene was the most strongly adsorbed aromatic in agreement with the strongly negative reaction order. Reactions with deuterium revealed an inverse kinetic isotope effect (KIE) suggesting that hydrogen bond breaking or making was not rate limiting. The cause of the inverse KIE was most likely related to the change in hybridization of the carbon $(\mathrm{C}-\mathrm{H})$ from $\mathrm{sp}^{2}$ to $\mathrm{sp}^{3}[23]$.

In this study we wanted to expand that work to examine the cascade reaction sequences phenylacetylene $\rightarrow$ styrene $\rightarrow$ ethylbenzene $\rightarrow$ ethylcyclohexane and 1-phenyl-1-propyne $\rightarrow$ cis/trans $-\beta$-methylstyrene $\rightarrow$ propylbenzene $\rightarrow$ propylcyclohexane and what happens when there are competitive reactions (Figs. 1 and 2). 


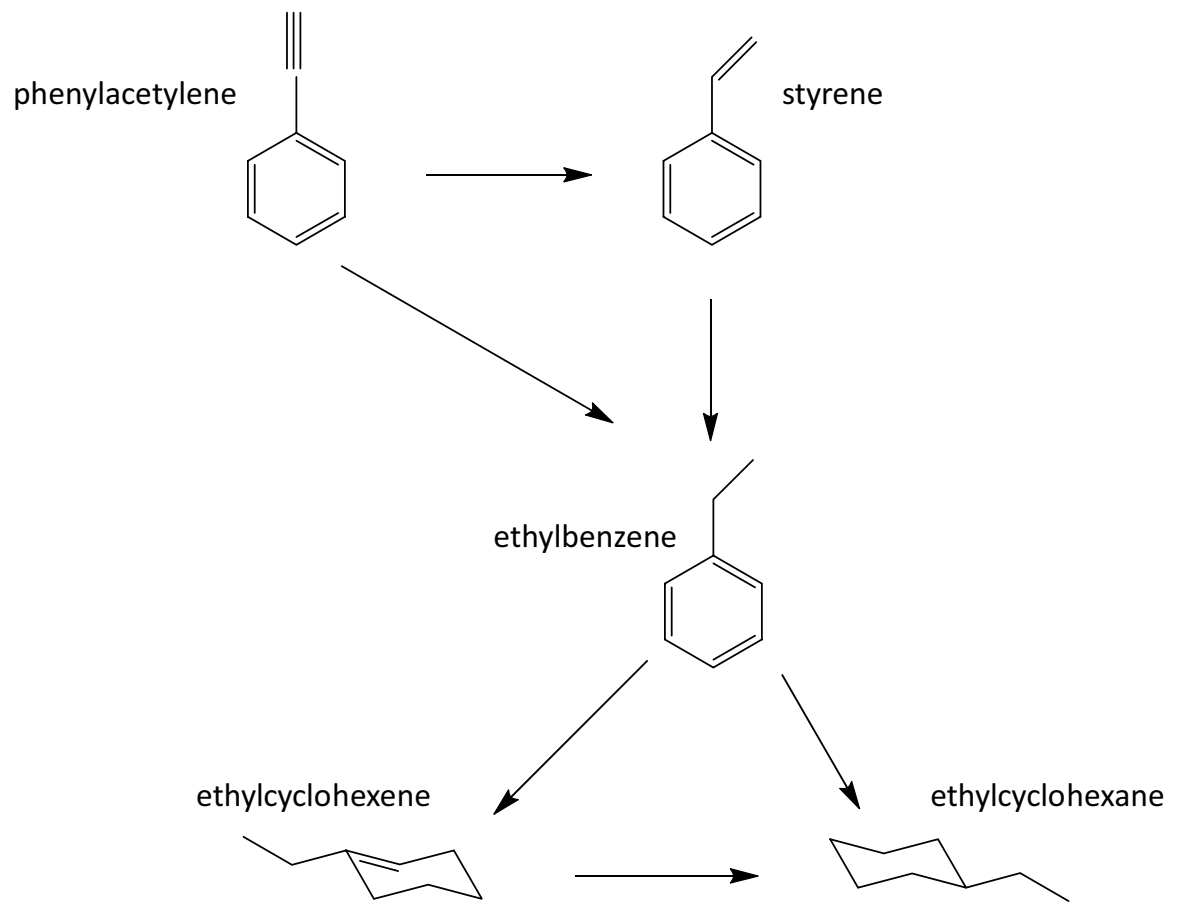

Fig. 1 Reaction scheme for phenylacetylene

\section{Experimental}

\section{Materials}

A rhodium/silica catalyst (M01078), which had been pre-reduced and stabilized, was supplied by Johnson Matthey and was used in all reactions. The catalyst, which had been prepared by impregnation using a Grace-Davison support, was characterized by Johnson Matthey and was found to have a rhodium loading of $2.5 \%$. The overall surface as measured by BET was $321 \mathrm{~m}^{2} \mathrm{~g}^{-1}$ with a pore size of $13.2 \mathrm{~nm}$. The metal dispersion measured by hydrogen chemisorption was $50 \%$, giving an average metal crystallite size of $2.2 \mathrm{~nm}$.

The solvent used, without further purification, was isopropyl alcohol (IPA, Sigma-Aldrich, $\geq 99.5 \%$ ). The reactants, phenylacetylene (ethynylbenzene Aldrich 98\%), 1-phenyl-1-propyne (Aldrich 99\%), ethylbenzene (Aldrich 99.5\%) and propylbenzene (Aldrich 98\%), were all used without further purification. Styrene (ethenylbenzene Sigma Aldrich, $\geq 99.5 \%$ ) was stored as a mixture with stabilizer (4-tertbutylcatechol) due to its tendency to polymerize when stored as a pure liquid. The stabilizer has the potential to interfere with the reaction hence the styrene was vacuum distilled shortly before use to obtain a pure sample. 


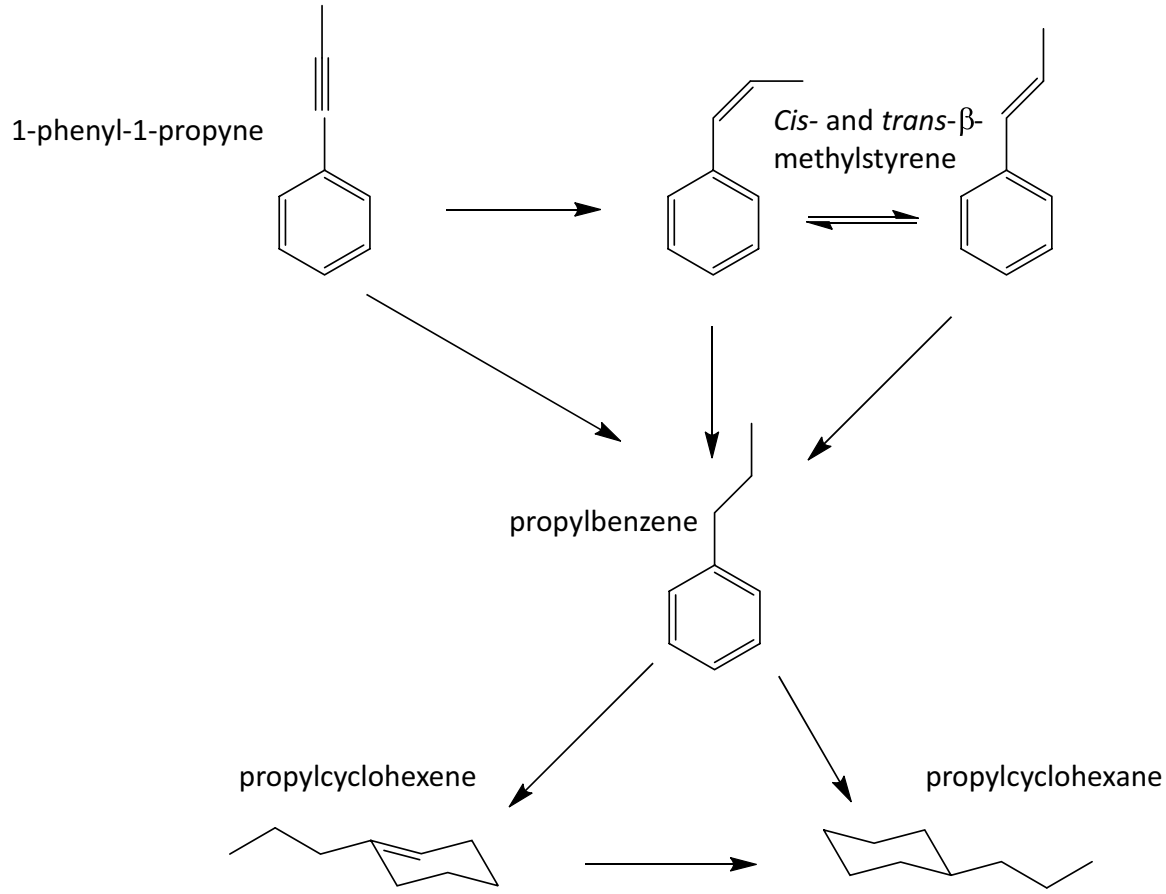

Fig. 2 Reaction scheme for 1-phenyl-1-propyne

\section{Hydrogenations}

The reactor used was a Büchi stirred autoclave with an oil jacket and a hydrogen on-demand system. This consisted of a 11 Büchi stirred tank reactor, a Büchi pressflow gas controller and a Julabo heating circulator for temperature control; a thermocouple connected to the heating circulator was used to monitor the temperature. $\mathrm{Rh} / \mathrm{SiO}_{2}$ catalyst $(0.1 \mathrm{~g})$ was suspended in IPA $(310 \mathrm{ml})$ and reduced under hydrogen or deuterium $\left(0.5 \mathrm{barg}, 100 \mathrm{ml} \mathrm{min}^{-1}\right)$ in the Büchi autoclave at $343 \mathrm{~K}$ for $30 \mathrm{~min}$ with stirring at $1000 \mathrm{rpm}$. After reduction the reactor was purged with nitrogen and the temperature was adjusted, if required, to the appropriate temperature for the reaction, usually $343 \mathrm{~K}$. The reactant $(10 \mathrm{mmol})$ or reactants were dissolved in IPA $(40 \mathrm{ml})$ by sonication for $15 \mathrm{~min}$ and degassed with argon for $25 \mathrm{~min}$. For competitive reactions $10 \mathrm{mmol}$ of each reactant was used. The reactant solution was injected into the reaction vessel and the reaction mixture stirred at $1000 \mathrm{rpm}$ for $15 \mathrm{~s}$. Stirring was ceased and nitrogen was then used to pressurize the reactor to $0.5 \mathrm{barg}$. The sample for time $=0 \mathrm{~min}$ was taken. The reactor was vented and pressurized with hydrogen or deuterium (3 barg) at a stirring speed of $1000 \mathrm{rpm}$. 


\section{Analysis}

Samples $(2.5 \mathrm{ml})$ were taken every $5 \mathrm{~min}$ for the first $0.5 \mathrm{~h}$, then every $10 \mathrm{~min}$ for the next $0.5 \mathrm{~h}$ before every $20 \mathrm{~min}$ for the next $2 \mathrm{~h}$. The samples were analyzed by an FID gas chromatograph with an HP 1701 column (30 m long, $0.25 \mathrm{~mm}$ diameter, $1.0 \mu \mathrm{m}$ film thickness). Typically, the mass balance of the reactions was better than $100 \pm 5 \%$

\section{Results}

\section{Single substrate reactions}

Phenylacetylene, 1-phenyl-1-propyne, styrene, ethylbenzene and propylbenzene were all reacted individually over the catalyst at $343 \mathrm{~K}$ at 3 barg hydrogen pressure. The ethylbenzene data for $343 \mathrm{~K}$ was similar to that published previously [23]. Figs. 3, 4, 5, 6 and 7 show the results from hydrogenation at $343 \mathrm{~K}$. The data show typical sequential reactions and highlight the rapid conversion of styrene to ethylbenzene, which was too fast to obtain a rate constant. The first order rate constants are reported in Table 1.

The activation energies for phenylacetylene and 1-phenyl-1-propyne were determined over the temperature range 313-343 K. The analysis is reported in the Supplementary Data. Phenylacetylene gave an activation energy of $56 \pm 4 \mathrm{~kJ} \mathrm{~mol}^{-1}$, while 1-phenyl-1-propyne gave an activation energy of $50 \pm 4 \mathrm{~kJ} \mathrm{~mol}^{-1}$.

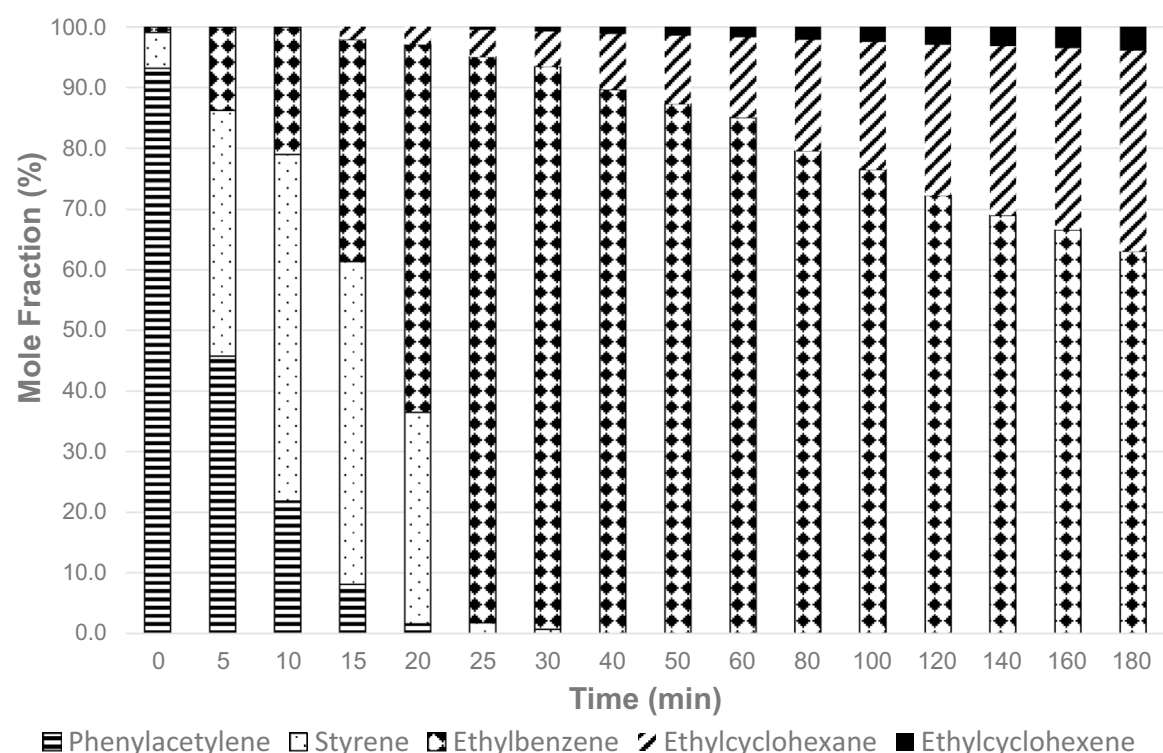

Fig. 3 Hydrogenation of phenylacetylene at $343 \mathrm{~K}, 3$ barg $\mathrm{H}_{2}$ and $10 \mathrm{mmol}$ reactant 


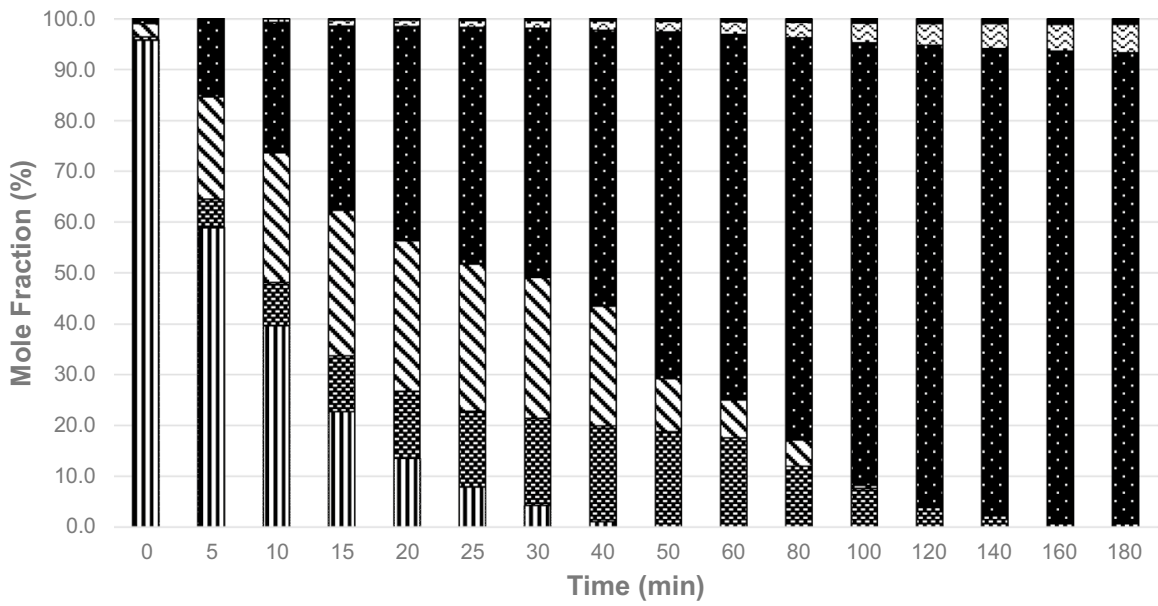
a1-Phenyl-1-propyne
占 Trans- $\beta$-methylstyrene $\mathbf{v}$ Cis- $\beta$-methylstyrene
- Propylbenzene
EPropylcyclohexane
- Propylcyclohexene

Fig. 4 Hydrogenation of 1-phenyl-1-propyne at $343 \mathrm{~K}, 3$ barg $\mathrm{H}_{2}$ and 10 mmol reactant

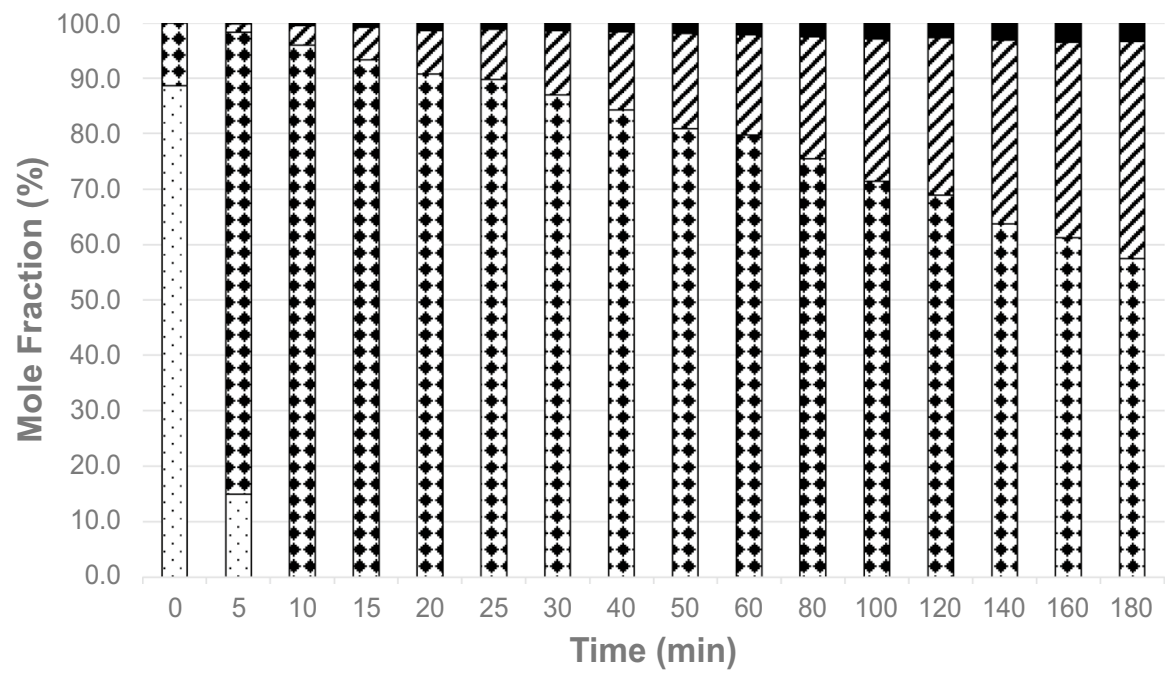

\section{¿Styrene Ethylbenzene $\boldsymbol{\nabla}$ Ethylcyclohexane Ethylcyclohexene}

Fig. 5 Hydrogenation of styrene at $343 \mathrm{~K}, 3$ barg $\mathrm{H}_{2}$ and 10 mmol reactant

\section{Deuterium reactions}

The hydrogenation of phenylacetylene, styrene and 1-phenyl-1-propyne was repeated using deuterium. The reaction profiles are shown in Figs. 8, 9 and 10. The rate of reaction significantly decreased for all substrates and this was reflected in the 


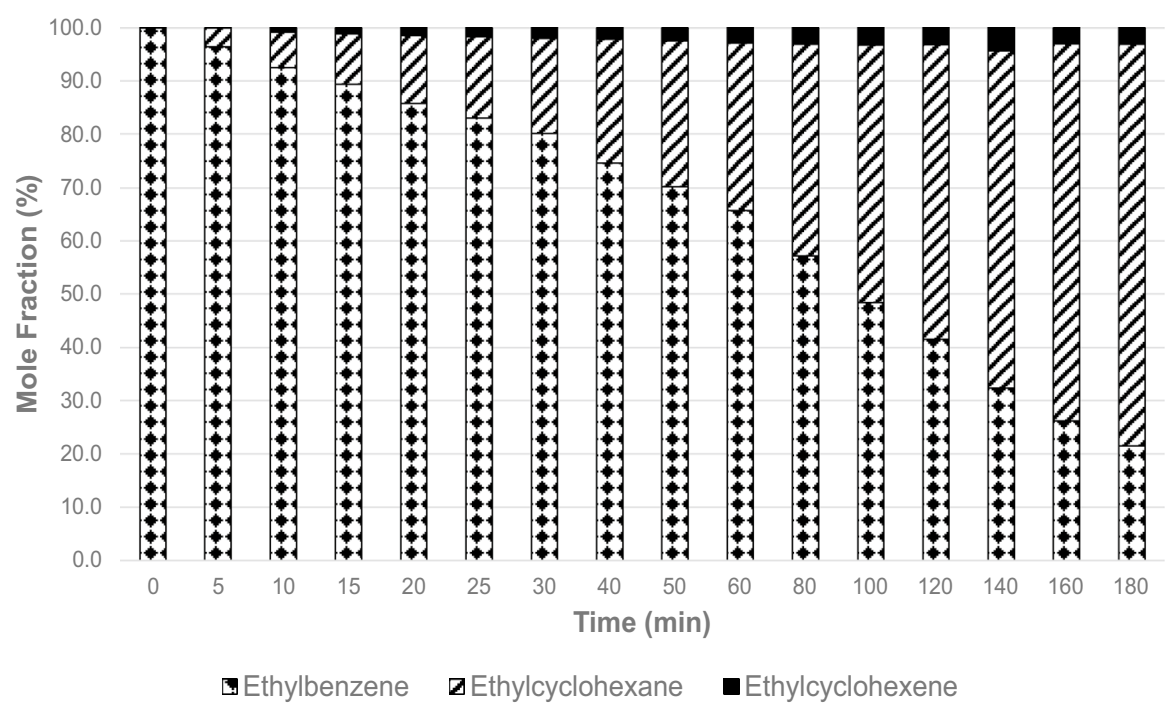

Fig. 6 Hydrogenation of ethylbenzene at $343 \mathrm{~K}, 3$ barg $\mathrm{H}_{2}$ and $10 \mathrm{mmol}$ reactant

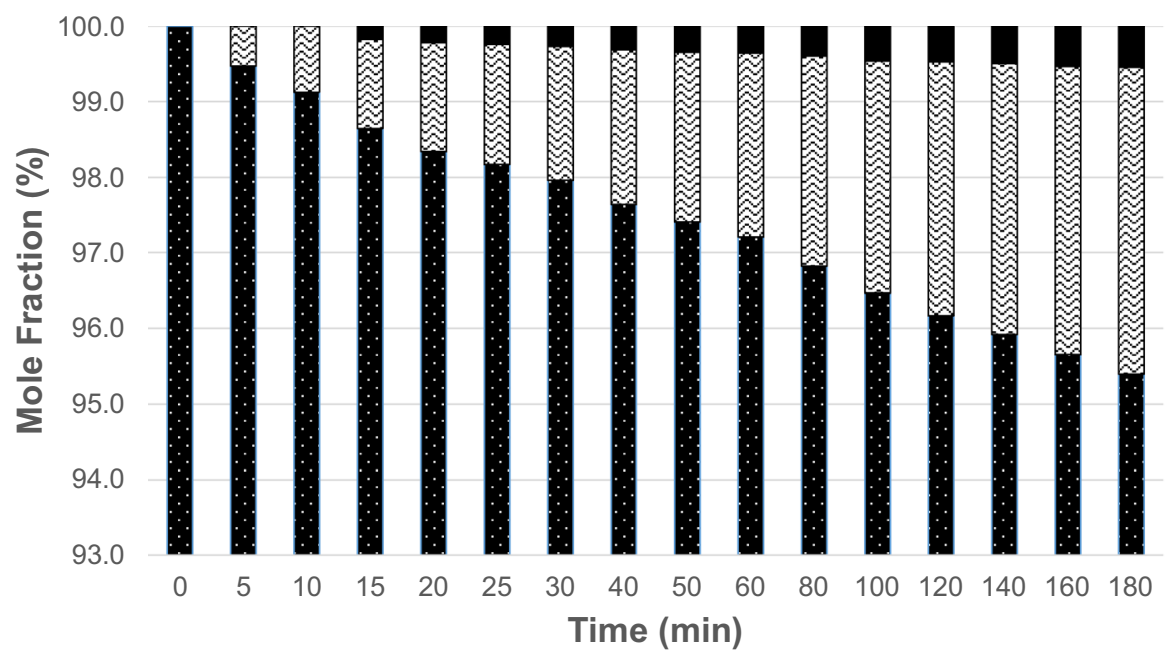

Propylbenzene $\quad$ Propylcyclohexane Propylcyclohexene

Fig. 7 Hydrogenation of propylbenzene at $343 \mathrm{~K}, 3$ barg $\mathrm{H}_{2}$ and $10 \mathrm{mmol}$ reactant 
Table 1 First order rate constants for phenylacetylene and ethylbenzene in different reactions

\begin{tabular}{|c|c|c|}
\hline Hydrogenation & Reactant & $\begin{array}{l}\text { 1st order rate } \\
\text { constant }\left(\min ^{-1}\right)\end{array}$ \\
\hline \multirow[t]{2}{*}{ Phenylacetylene } & Phenylacetylene & 0.1614 \\
\hline & Ethylbenzene $^{\mathrm{a}}$ & 0.0027 \\
\hline Styrene & Ethylbenzene $^{\mathrm{b}}$ & 0.0042 \\
\hline Ethylbenzene & Ethylbenzene & 0.0072 \\
\hline 1-Phenyl-1-propyne & 1-Phenyl-1-propyne & 0.1028 \\
\hline Propylbenzene & Propylbenzene & 0.0008 \\
\hline
\end{tabular}

${ }^{\mathrm{a}}$ Measured after all phenylacetylene and styrene had been reacted

${ }^{\mathrm{b}}$ Measured after all styrene had been reacted

${ }^{\mathrm{c}} \mathrm{NR}$, no reaction detected

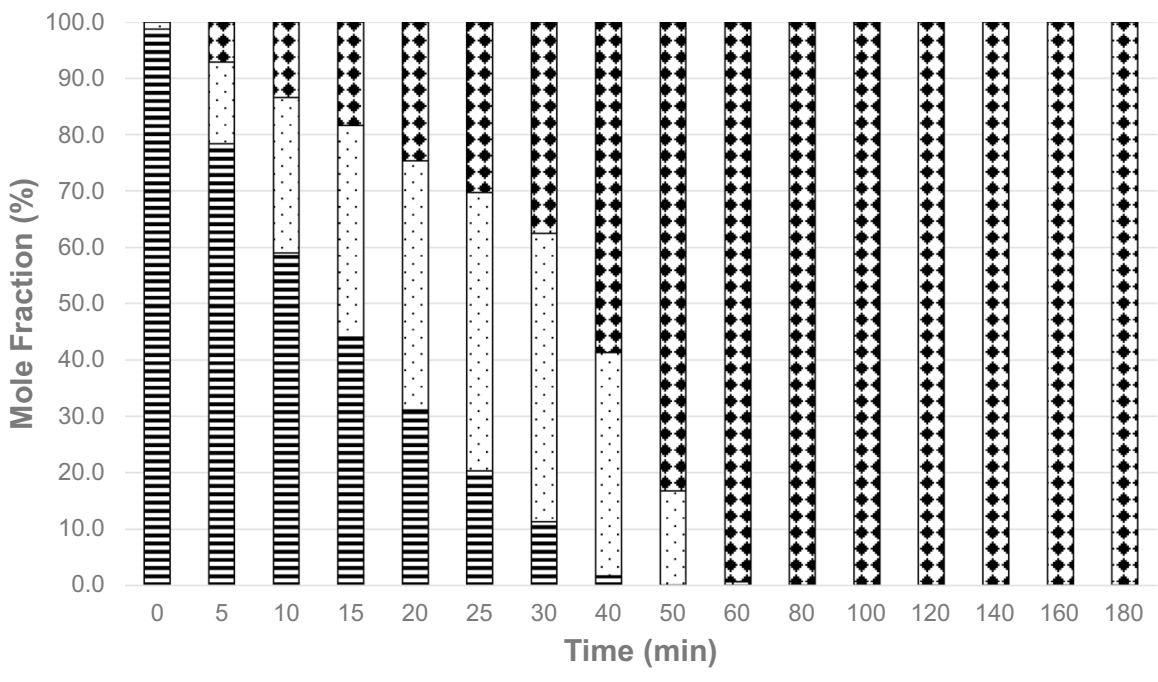

EPhenylacetylene $\nabla$ Styrene Ethylbenzene

Fig. 8 Hydrogenation of phenylacetylene at $343 \mathrm{~K}, 3$ barg $\mathrm{D}_{2}$ and $10 \mathrm{mmol}$ reactant

first order rate constants reported in Table 2 and the measured kinetic isotope effect $\left(\mathrm{KIE}, \mathrm{k}_{\mathrm{H}} / \mathrm{k}_{\mathrm{D}}\right)$.

\section{Competitive reactions}

Phenylacetylene was hydrogenated in the presence of styrene (Fig. 11) and ethylbenzene (Fig. 12). Table 3 reports the first-order rate constants for the reactions. In both cases both substrates have reduced activity. Phenylacetylene was hydrogenated in the presence of 1-phenyl-1-propyne to assess the effect of an internal and terminal alkene on their reactivity. The conversion with time is shown in Fig. 13, clearly the reactivity of both reactants was reduced but the 


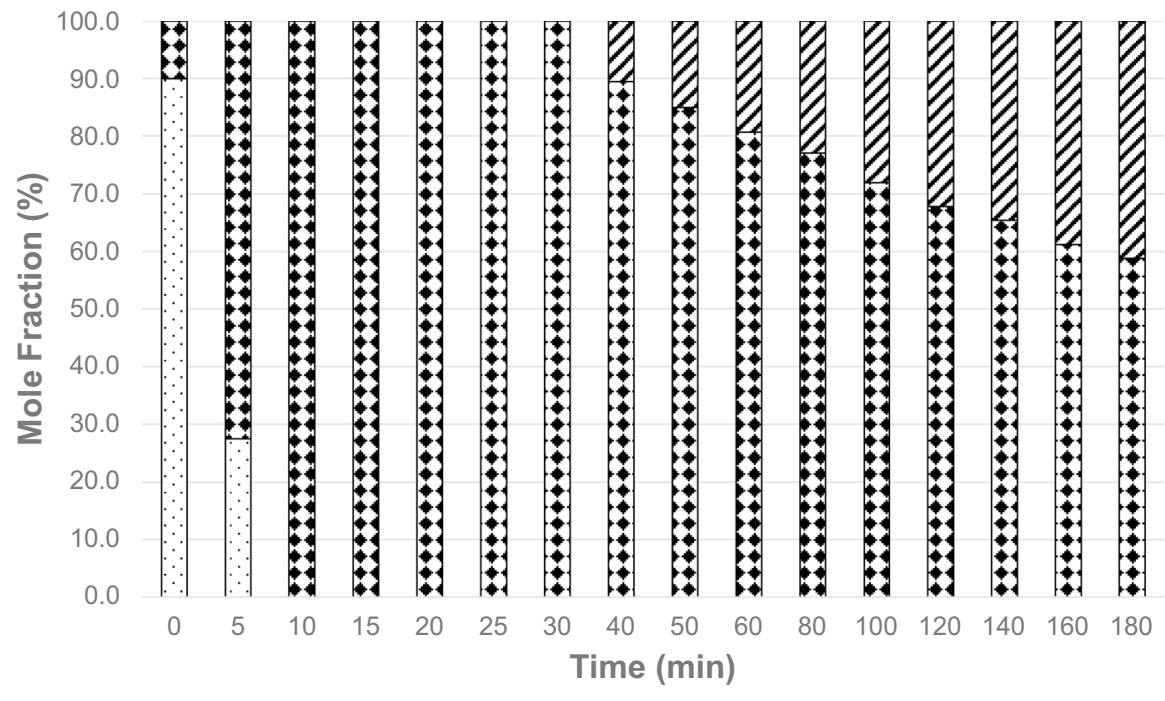

ఐStyrene Ethylbenzene Ethylcyclohexane

Fig. 9 Hydrogenation of styrene at $343 \mathrm{~K}, 3$ barg $\mathrm{D}_{2}$ and 10 mmol reactant

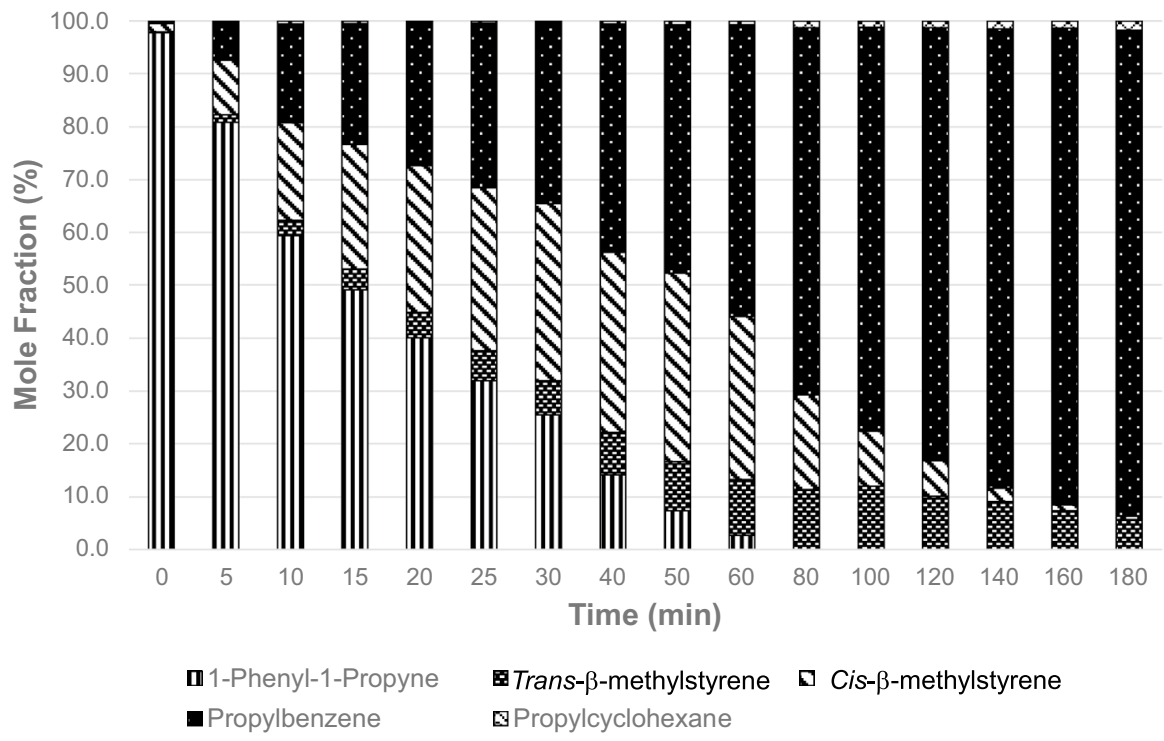

Fig. 10 Hydrogenation of 1-phenyl-1-propyne at $343 \mathrm{~K}, 3$ barg $\mathrm{D}_{2}$ and 10 mmol reactant

effect was most noticeable with 1-phenyl-1-propyne where conversion was significantly inhibited until $~ 80 \%$ of the phenylacetylene was hydrogenated. The full reaction profile is shown in the Supplementary data. The first order rate constants are reported in Table 3. 
Table 2 First order rate constants for deuterium reactions

\begin{tabular}{|c|c|c|c|}
\hline Hydrogenation & Reactant & $\begin{array}{l}\text { 1st order rate constant }\left(\mathrm{k}_{\mathrm{D}}\right. \\
\left.\min ^{-1}\right)\end{array}$ & $\mathrm{k}_{\mathrm{H}} / \mathrm{k}_{\mathrm{D}}$ \\
\hline \multirow[t]{2}{*}{ Phenylacetylene/ $\mathrm{D}_{2}$} & Phenylacetylene & 0.0628 & 2.6 \\
\hline & Ethylbenzene $^{\mathrm{a}}$ & $\mathrm{NR}^{\mathrm{c}}$ & - \\
\hline Styrene/D 2 & Ethylbenzene $^{\mathrm{b}}$ & 0.0027 & 1.6 \\
\hline 1-Phenyl-1-propyne/D 2 & 1-Phenyl-1-propyne & 0.0450 & 2.1 \\
\hline
\end{tabular}

${ }^{a}$ Measured after all phenylacetylene and styrene had been reacted

${ }^{\mathrm{b}}$ Measured after all styrene had been reacted

${ }^{\mathrm{c}} \mathrm{NR}$, no reaction detected

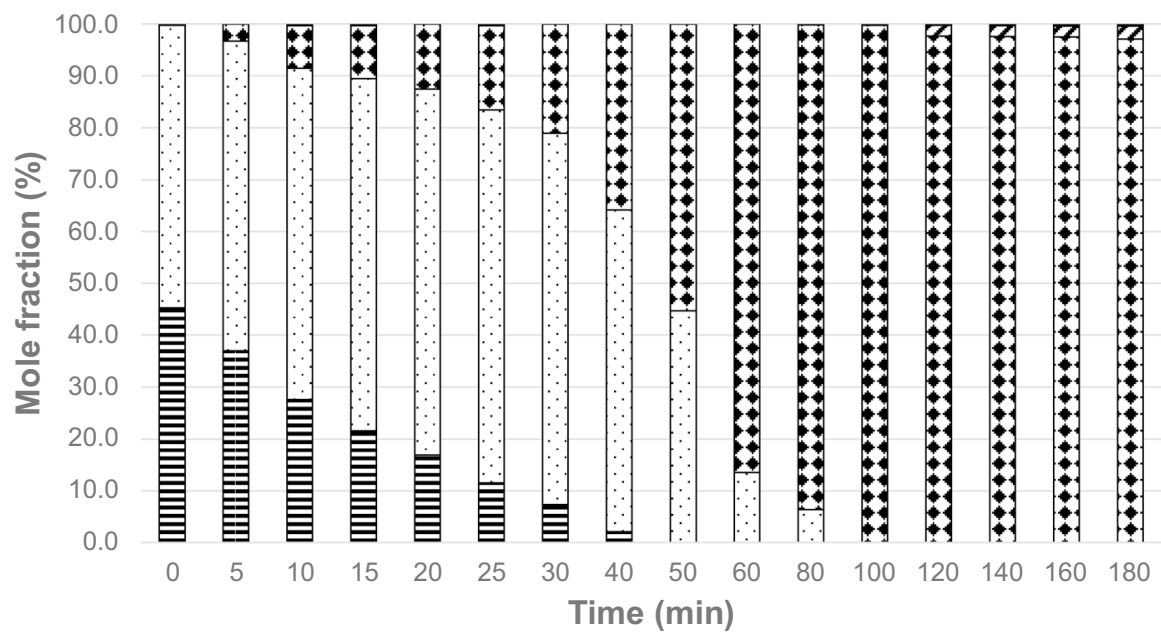

EPhenylacetylene $\mathbf{0}$ Styrene $\mathbf{0}$ Ethylbenzene $\boldsymbol{\nabla}$ Ethylcyclohexane $\mathbf{\square}$ Ethylcyclohexene

Fig. 11 Competitive hydrogenation of phenylacetylene and styrene at $343 \mathrm{~K}, 3$ barg $\mathrm{H}_{2}$ and $10 \mathrm{mmol}$ of each reactant

To determine whether the presence of phenylacetylene inhibited isomerization between cis- $\beta$-methylstyrene and trans- $\beta$-methylstyrene, the cis:trans ratio was determined at equal conversion of 1-phenyl-1-propyne. At $60 \%$ conversion the cis:trans ratio obtained when only 1-phenyl-1-propyne was hydrogenated was 3.0, however when 1-phenyl-1-propyne and phenylacetylene were co-hydrogenated, the cis:trans ratio for methylstyrene was 4.8 indicating that phenylacetylene hydrogenation inhibited isomerization.

The competitive reaction of 1-phenyl-1-propyne and propylbenzene was performed to compare with the phenylacetylene/ethylbenzene reaction. The results are shown in Fig. 14. The unexpected result was the increase in hydrogenation rate of 1-phenyl-1-propyne (Table 3), which contrasted with phenylacetylene/ 


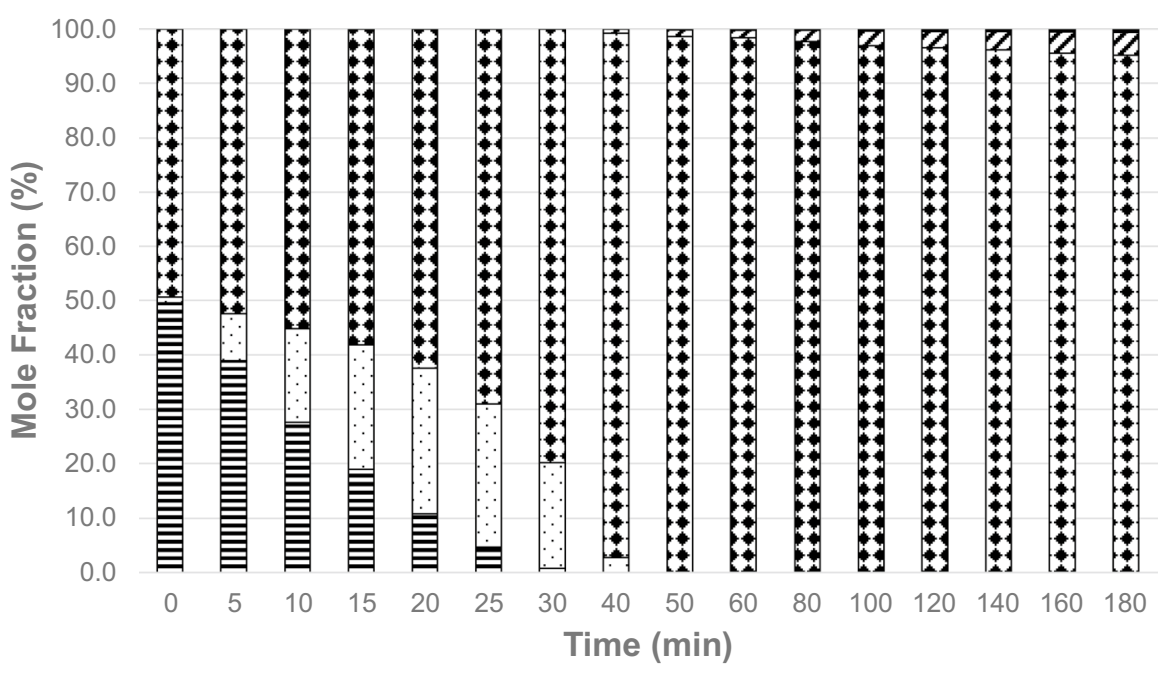

EPhenylacetylene $\square$ Styrene Ethylbenzene $\boldsymbol{a}$ Ethylcyclohexane Ethylcyclohexene

Fig. 12 Competitive hydrogenation of phenylacetylene and ethylbenzene at $343 \mathrm{~K}, 3$ barg $\mathrm{H}_{2}$ and $10 \mathrm{mmol}$ of each reactant

Table 3 First order rate constants obtained from phenylacetylene and 1-phenyl-1-propyne hydrogenation in competitive reactions

\begin{tabular}{|c|c|c|}
\hline Hydrogenation & Reactant & $\begin{array}{l}1 \text { st order } \\
\text { rate con- } \\
\text { stant }\end{array}$ \\
\hline \multirow[t]{2}{*}{ Phenylacetylene/styrene } & Phenylacetylene & 0.0503 \\
\hline & Ethylbenzene $^{\mathrm{a}}$ & 0.0001 \\
\hline \multirow[t]{2}{*}{ Phenylacetylene/ethylbenzene } & Phenylacetylene & 0.0648 \\
\hline & Ethylbenzene $^{\mathrm{a}}$ & 0.0003 \\
\hline \multirow[t]{2}{*}{ Phenyl acetylene/1-phenyl-1-propyne } & Phenyl acetylene & 0.0397 \\
\hline & 1-Phenyl-1-propyne ${ }^{\mathrm{b}}$ & 0.0033 \\
\hline 1-Phenyl-1-propyne/propylbenzene & 1-Phenyl-1-propyne & 0.1307 \\
\hline
\end{tabular}

Conditions: $343 \mathrm{~K}, 3$ barg, $10 \mathrm{mmol}$ of each reactant

${ }^{a}$ Measured after all phenylacetylene and styrene were hydrogenated

${ }^{\mathrm{b}}$ Measured with phenylacetylene present, after all phenylacetylene had reacted the rate constant was estimated as similar to that obtained with a fresh catalyst

ethylbenzene where the rate of alkyne hydrogenation decreased. The cis:trans ratio for methylstyrene was also changed, with a value of 4.4 at $~ 60 \%$ conversion of 1-phenyl-1-propyne in the presence of propylbenzene, whereas when only 1-phenyl-1-propyne was hydrogenated the cis:trans ratio obtained was 3.0. 


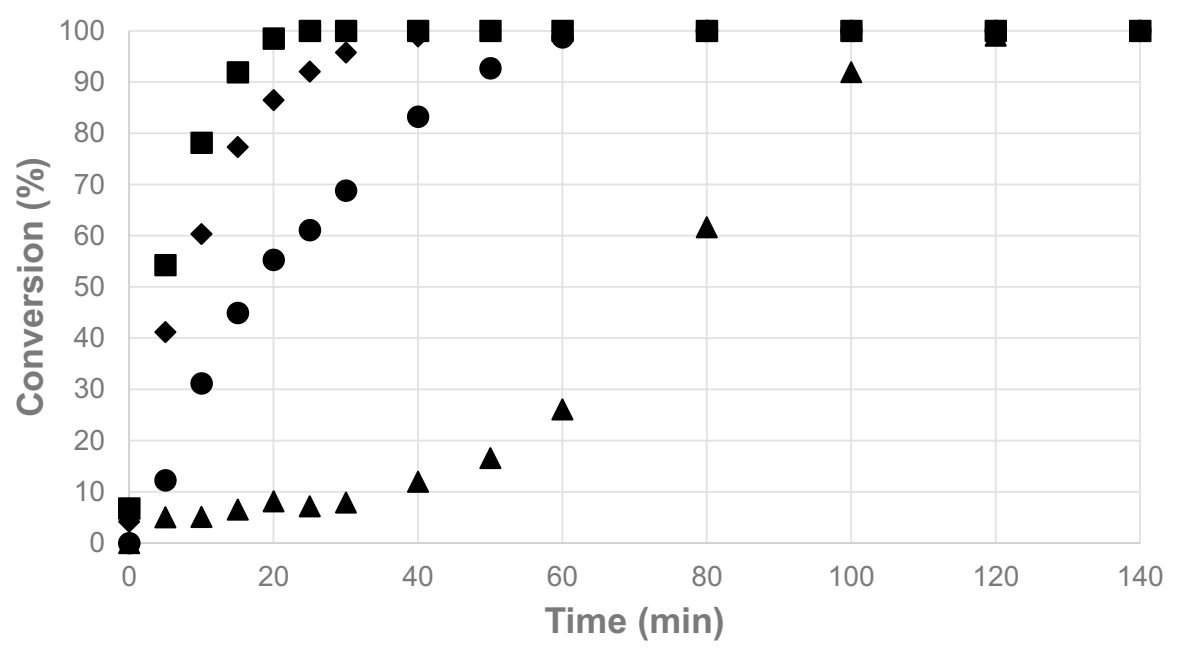

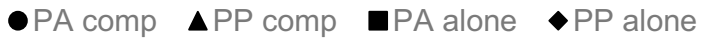

Fig. 13 Competitive hydrogenation of 1-phenyl-1-propyne (PP) and phenylacetylene (PA) at $343 \mathrm{~K}, 3$ barg $\mathrm{H}_{2}$ and $10 \mathrm{mmol}$ of each reactant

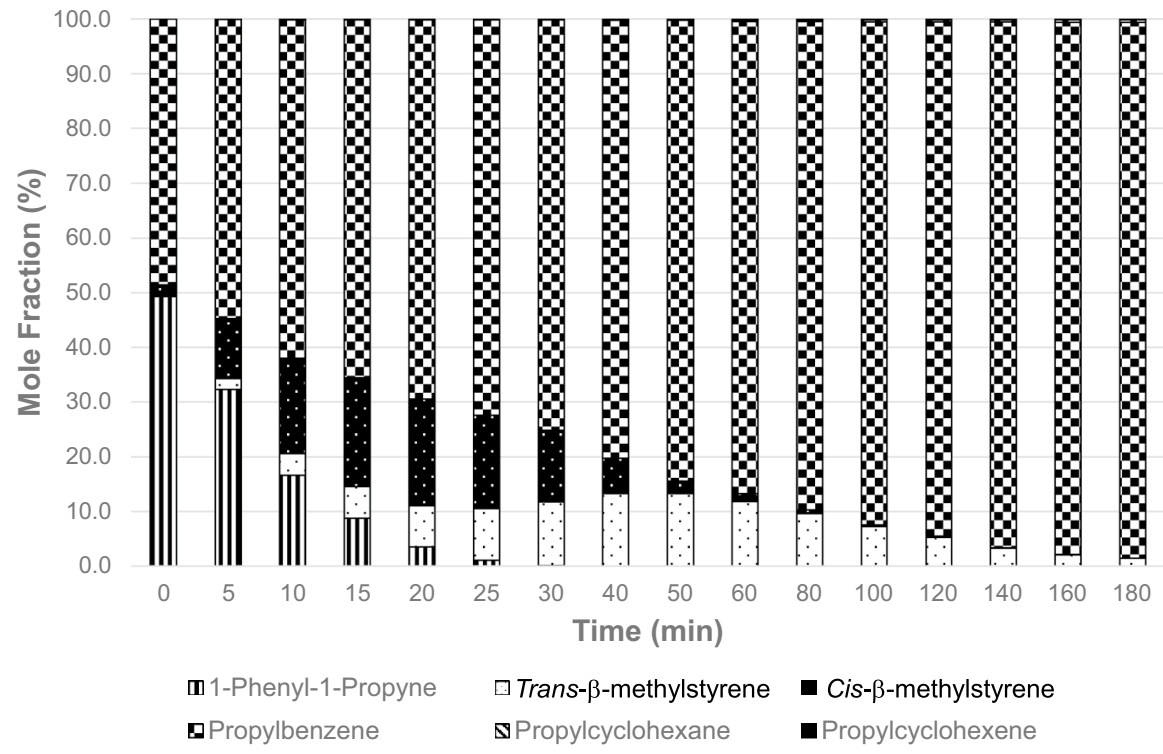

Fig. 14 Competitive hydrogenation of 1-phenyl-1-propyne and propylbenzene at $343 \mathrm{~K}, 3$ barg $\mathrm{H}_{2}$ and $10 \mathrm{mmol}$ of each reactant 


\section{Discussion}

In this study the hydrogenation of alkyne, alkene and aromatic functionalities have been examined over a Rh/silica catalyst. Over a fresh catalyst the order of reactivity was styrene $>$ phenylacetylene $\gg$ ethylbenzene. This order was to be expected as it is well known that alkenes hydrogenate faster than the respective alkyne [4]. When the hydrogenation of 1-phenyl-1-propyne was examined, it was found that the rate of hydrogenation was slower than that of phenylacetylene. Again, this was expected as a terminal alkyne in general reacts faster than an internal alkyne [15] due to the steric constraints inherent in adsorption of the internal alkyne. Nevertheless, in contrast to phenylacetylene, 1-phenyl-1-propyne hydrogenated faster than its alkene.

When phenylacetylene was hydrogenated it produced styrene, which was then hydrogenated to ethylbenzene, which was subsequently hydrogenated to ethylcyclohexane. It is also possible for phenylacetylene to be directly hydrogenated to ethylbenzene. On examining the cascade hydrogenation starting with phenylacetylene (Fig. 3) styrene did not hydrogenate faster than phenylacetylene, in contrast to its behavior over a fresh catalyst. As phenylacetylene was hydrogenated the concentration of styrene increased and only once the majority of phenylacetylene had been consumed did styrene react faster but even then much slower than over a fresh system (rate of styrene hydrogenation over a fresh catalyst was $22.4 \mathrm{mmol} \mathrm{min} \mathrm{m}^{-1}$ compared to $7.8 \mathrm{mmol} \mathrm{min}^{-1} \mathrm{~g}^{-1}$ after phenylacetylene hydrogenation). Therefore, even when no phenylacetylene was left in the system, the rate of styrene hydrogenation was decreased. This may be due to carbon deposition or due to structural changes in the rhodium crystallite. Ethylbenzene hydrogenation in the cascade was also reduced to $\sim 1 / 3$ rd of the rate over a fresh catalyst. Given that there was the same rate reduction for alkene and aromatic hydrogenation it seems more likely that the activity was reduced due to a loss in active sites from carbonaceous deposits rather than structural changes.

1-Phenyl-1-propyne was converted to $c i s$ - $\beta$-methylstyrene, which isomerized to trans- $\beta$-methylstyrene and/or hydrogenated to propylbenzene. The data shown in Fig. 4 revealed that $c i s-\beta$-methylstyrene was hydrogenated to propylbenzene faster than it isomerized to trans- $\beta$-methylstyrene and that hydrogenation of trans- $\beta$-methylstyrene was much slower than that of cis- $\beta$-methylstyrene. This slow rate of hydrogenation of the trans-isomer has been observed with rhodium and iridium catalysts [24] and more generally with C4 and C5 systems over palladium catalysts $[19,25]$ and has been explained by suggesting that the transisomer is far more strongly bound than the cis-isomer.

When hydrogen was replaced by deuterium the rate of reaction of all substrates reduced resulting in a positive kinetic isotope effect (KIE) (Table 2). KIEs are rarely reported but a value of 1.8 has been reported for phenylacetylene over $\mathrm{Rh} /$ silica [26], which is in reasonable agreement with our value of 2.6. The rate of

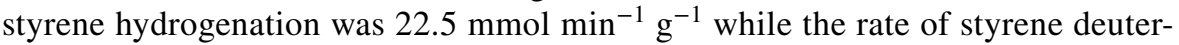

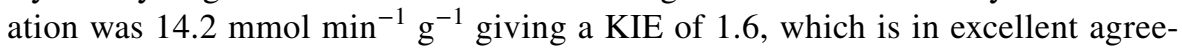
ment with the literature, where KIE for styrene hydrogenation was reported at 
1.4 [26]. These KIE values suggest a primary KIE where hydrogen is directly involved in a bond making step. Note that the KIE value for phenylacetylene and 1-phenyl-1-propyne are similar suggesting a similar rate determining step. The KIE value observed for ethylbenzene hydrogenation/deuteration of 1.6 obtained after styrene hydrogenation was interesting because ethylbenzene hydrogenation/ deuteration over a fresh catalyst gave rise to an inverse KIE of 0.4 [23]. This indicates a change in rate determining step between ethylbenzene hydrogenation over a fresh catalyst and over a catalyst used for styrene hydrogenation. This applies also to a catalyst used for phenylacetylene hydrogenation even though no KIE was measured for ethylbenzene hydrogenation, as it is clear from the lack of reaction of ethylbenzene that the rate of hydrogenation has decreased significantly when deuterium is used (Fig. 8). When hydrogenated over a fresh catalyst the rate determining step for ethylbenzene was suggested to be the change in sp-hybridization going from $\mathrm{sp}^{2}$ to $\mathrm{sp}^{3}$ [23] in keeping with an inverse KIE. Clearly this change in hybridization is still occurring but is no longer rate determining. It is likely that the new rate determining step involves hydrogen addition, which may be mediated by the carbonaceous deposit left by styrene.

To investigate the cascade reaction in more detail a competitive reaction between phenylacetylene and styrene was performed. The rate of styrene hydrogenation after all phenylacetylene was consumed was the same as that observed during the phenylacetylene cascade $\left(7.4 \mathrm{mmol} \mathrm{g} \mathrm{min}^{-1}\right.$ c.f. $\left.7.8 \mathrm{mmol} \mathrm{g} \mathrm{min}^{-1}\right)$. The rate of phenylacetylene hydrogenation was suppressed with the rate constant dropping from 0.1614 to $0.0503 \mathrm{~min}^{-1}$ indicating that the styrene inhibited the phenylacetylene hydrogenation. This is a similar result to that found over Pd [15], where competitive adsorption between phenylacetylene and styrene was detected and the rate of

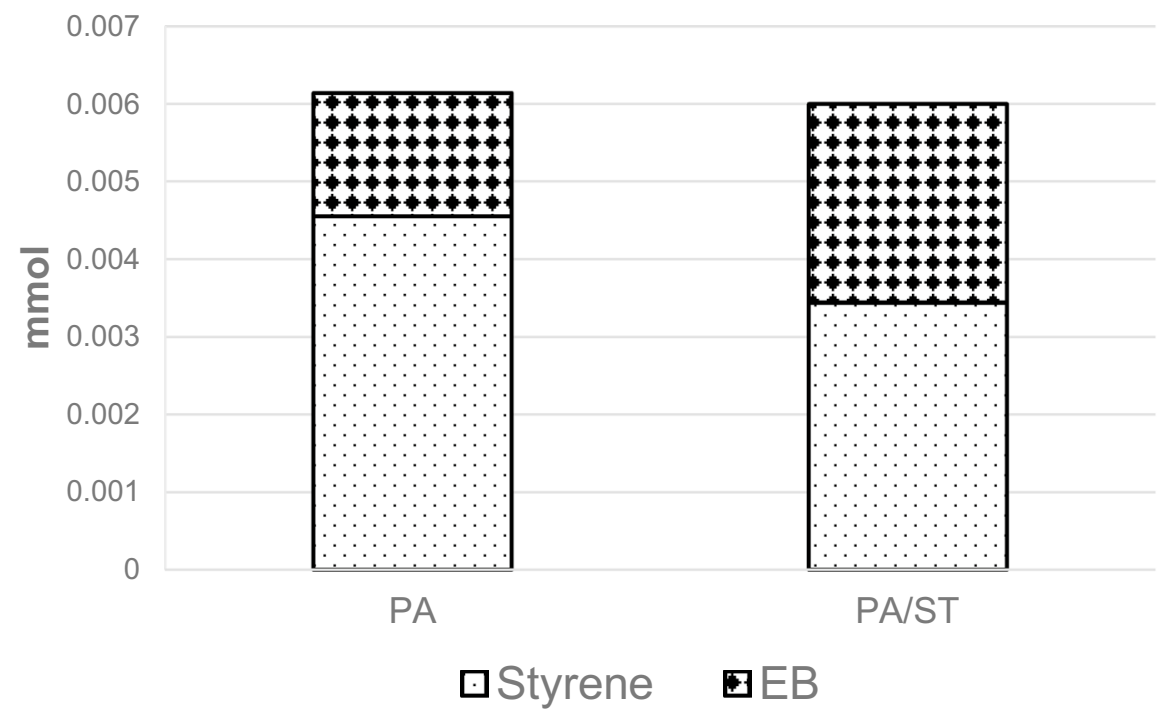

Fig. 15 Selectivity at 55\% conversion of phenylacetylene during phenylacetylene hydrogenation and phenylacetylene/styrene co-hydrogenation. Conditions, $343 \mathrm{~K}, 10 \mathrm{mmol}$ of each substrate and 3 barg 
phenylacetylene hydrogenation was also decreased. A more detailed analysis of the data revealed that the yield of ethylbenzene was enhanced during phenylacetylene hydrogenation. Fig. 15 compares the amounts of styrene and ethylbenzene produced at 55\% conversion of phenylacetylene for both reactions. Overall yield was the same but reaction with styrene present produced more ethylbenzene (note that the starting styrene has been subtracted out). This change in selectivity indicates that either styrene reactivity had increased and/or phenylacetylene was producing more ethylbenzene directly. The presence of sub-surface hydrogen in rhodium has been postulated previously [20] and this behavior would be expected if sub-surface hydrogen was increased as this type of hydrogen has been shown to enhance alkyne to alkane and alkene to alkane transformations [5-7]. The last section of the cascade was ethylbenzene hydrogenation to ethylcyclohexane. The rate of this hydrogenation was dramatically reduced with the rate constant going from $2.7 \times 10^{-3} \mathrm{~min}^{-1}$ in the standard phenylacetylene cascade to $0.1 \times 10^{-3} \mathrm{~min}^{-1}$ when phenylacetylene and styrene were competitively hydrogenated. The hydrogenation of the aromatic ring requires a larger surface site than alkyne or alkene hydrogenation and is more susceptible to poisoning by a carbonaceous deposit [4].

To further examine the effect of a competitive species phenylacetylene was reacted in the presence of ethylbenzene. In this case the assumption was that given that ethylbenzene was so much more weakly adsorbed it would have little or no effect, especially as it had been so negatively affected in the phenylacetylene/styrene reaction. However the rate constant for phenylacetylene hydrogenation was reduced by $\sim 60 \%$, while rate of styrene hydrogenation was also reduced $\left(1.2 \mathrm{mmol} \mathrm{g}^{-1} \mathrm{~min}^{-1}\right.$ c.f. $7.8 \mathrm{mmol} \mathrm{g}^{-1} \mathrm{~min}^{-1}$ ). Therefore, even the most weakly adsorbed species inhibits the hydrogenation of the two more strongly adsorbed species, implying that all three species are co-adsorbed. This is surprising as ethylbenzene has a larger site requirement than either phenylacetylene or styrene. Indeed, the classical interpretation of the low alkene and aromatic reactivity is that the strength of the alkyne adsorption is such that it inhibits re-adsorption of both the alkene and aromatic. However, it has been shown that both alkene and aromatic do adsorb in the presence of the alkyne $[15,27,28]$, therefore the lack of activity is not due to lack of adsorption but lack of reactivity. Such lack of reactivity is most likely due to an inability of the catalyst to deliver sufficient hydrogen or changes in the mode of adsorption for phenylacetylene (see below).

When phenylacetylene and 1-phenyl-1-propyne were competitively hydrogenated, the hydrogenation of 1-phenyl-1-propyne was significantly inhibited ( 10\% conversion) until $80 \%$ of the phenylacetylene was hydrogenated (Fig. 13) after which the rate was typical of that found over a fresh catalyst. Very similar results were obtained over Pd catalysts when 1-phenyl-1-propyne was hydrogenated in the presence of 1-pentyne [18]. In that case 1-phenyl-1-propyne hydrogenation was inhibited until $\sim 90 \%$ conversion of 1-pentyne. This revealed that phenylacetylene is much more strongly adsorbed than 1-phenyl-1-propyne but once removed the rate for 1-phenyl-1-propyne hydrogenation recovers. Nevertheless, the reactivity for phenylacetylene hydrogenation was reduced by $\sim 75 \%$. The reduction in phenylacetylene hydrogenation activity could be related to hydrogen availability but the mode of adsorption of phenylacetylene may also play a part. Analysis of the modes 
of adsorption for phenylacetylene on rhodium by Iucci et al. [29] revealed that the main mode that results in hydrogenation to styrene is di- $\sigma$ adsorbed with the phenyl group sitting up from the surface. In contrast end-on adsorption perpendicular to the surface found with phenylacetylene on $\mathrm{Cu}$ [30] (along with di- $\sigma$ adsorbed) did not hydrogenate to styrene. Although this mode of adsorption has not been specifically identified on $\mathrm{Rh}$ with phenylacetylene, it has been identified on Pt [14] and for propyne adsorption on $\mathrm{Rh}$ [31]. Therefore, if the addition of a second component resulted in an increase in this mode of adsorption at the expense of the di- $\sigma$ then the rate of hydrogenation would decrease.

The competitive reaction between 1-phenyl-1-propyne and propylbenzene was also examined (Fig. 12) and a surprising result was observed. The rate of hydrogenation of 1-phenyl-1-propyne increased in the presence of propylbenzene. Rate enhancements in competitive reactions have been observed previously $[15,18,19]$ and competitive reactions involving propylbenzene have also shown rate enhancements [23]. However, these reactions have typically involved reactions between similar species, e.g., toluene/propylbenzene [23] or 1-pentyne/2-pentyne [15, 19]. In all cases the explanation relates to an increase in effective hydrogen concentration and/or a change in the strength of adsorption: both explanations have been proposed $[15,19,23]$. For 1-phenyl-1-propyne it is more likely that there was an increase in the hydrogen flux for hydrogenation as the adsorbed state most likely remained di- $\sigma$ [32]. At the same time there was a decrease in the hydrogen species active in methylstyrene isomerization. Note that the hydrogen active for isomerization is not active for hydrogenation [7, 33] hence it is possible to enhance one and inhibit the other. Two states of adsorbed hydrogen have been identified on rhodium [34-38]: a surface state and a sub-surface state similar to palladium.

\section{Conclusions}

The cascade reactions of phenylacetylene to ethylcyclohexane and 1-phenyl-1-propyne to propylcyclohexane were studied individually, under deuterium and competitively at $343 \mathrm{~K}$ and 3 barg pressure. Both systems gave similar activation energies for alkyne hydrogenation suggesting a similar adsorbed state that is active. From adsorbed state data in the literature for phenylacetylene and 1-phenyl-1-propyne $[29,33]$, this state is most likely to be the di- $\sigma$ adsorbed. Over a fresh catalyst the order of reactivity was styrene $>$ phenylacetylene $\gg$ ethylbenzene. Whereas with the cascade hydrogenation starting with phenylacetylene, styrene hydrogenated much slower phenylacetylene even once all the phenylacetylene was hydrogenated. The activity of ethylbenzene was also reduced in the cascade reaction and after styrene hydrogenation. These reductions in rate were likely due to carbon laydown from phenylacetylene and styrene. Similar behavior was observed with the 1-phenyl-1-propyne cascade. However, the data also indicated that cis- $\beta$-methylstyrene hydrogenated to propylbenzene faster than it isomerized to trans- $\beta$-methylstyrene and that trans- $\beta$-methylstyrene hydrogenated to propylbenzene more slowly that the cis-isomer, a well-known "trans-effect" in hydrogenation [11]. Deuterium experiments revealed similar positive KIEs for phenylacetylene and 1-phenyl-1-propyne. 
Styrene also gave a positive KIE but surprisingly ethylbenzene hydrogenation/deuteration gave a KIE of 1.6 obtained after styrene hydrogenation in contrast to the inverse KIE of 0.4 found with ethylbenzene hydrogenation/deuteration over a fresh catalyst [23]. This indicated a change in rate determining step between ethylbenzene hydrogenation over a fresh catalyst and over a catalyst used for styrene hydrogenation (or phenylacetylene hydrogenation even though no KIE was measured for ethylbenzene hydrogenation, as it is clear from the lack of reaction of ethylbenzene that the rate of hydrogenation has decreased significantly when deuterium is used). Competitive hydrogenation between phenylacetylene and styrene reduced the rate of phenylacetylene hydrogenation but increased selectivity to ethylbenzene suggesting a change in the flux of sub-surface hydrogen. Therefore, the behavior observed with a rhodium catalyst is consistent with two states of hydrogen on rhodium: surface and sub-surface species [34]. The competitive hydrogenation of phenylacetylene and 1-phenyl-1-propyne revealed that phenylacetylene is much more strongly adsorbed than 1-phenyl-1-propyne. Nevertheless, the reactivity for phenylacetylene hydrogenation was reduced by $\sim 75 \%$, which may be related to hydrogen availability or a change in the mode of adsorption of phenylacetylene. In the competitive reaction between 1-phenyl-1-propyne and propylbenzene, the rate of hydrogenation of 1-phenyl-1-propyne was increased and the rate of isomerization was decreased. Behavior such as this is usually related to a change in strength of adsorption or hydrogen flux. For 1-phenyl-1-propyne hydrogenation it is more likely that there was an increase in the hydrogen flux for hydrogenation and a decrease in the hydrogen species active in methylstyrene isomerization.

Supplementary Information The online version contains supplementary material available at https://doi. org/10.1007/s11144-021-02039-z.

Author contributions JWG (ORCID: 0000-0003-3642-3817): Funding acquisition, Validation, Formal analysis, Investigation. SDJ (ORCID 0000-0003-1257-5533): Supervision, Project administration, Formal analysis, Writing.

\section{Declarations}

Conflict of interest The authors declare that they have no conflict of interest.

Open Access This article is licensed under a Creative Commons Attribution 4.0 International License, which permits use, sharing, adaptation, distribution and reproduction in any medium or format, as long as you give appropriate credit to the original author(s) and the source, provide a link to the Creative Commons licence, and indicate if changes were made. The images or other third party material in this article are included in the article's Creative Commons licence, unless indicated otherwise in a credit line to the material. If material is not included in the article's Creative Commons licence and your intended use is not permitted by statutory regulation or exceeds the permitted use, you will need to obtain permission directly from the copyright holder. To view a copy of this licence, visit http://creativecommons.org/licen ses/by/4.0/.

\section{References}

1. de Wilde P (1874) Ber Dtsch Chem Ges 7:352-357 
2. Sheridan J (1945). J Chem Soc. https://doi.org/10.1039/jr9450000470

3. Bond GC (1955) The addition of hydrogen to carbon-carbon triple bonds. In: Emmett PH (ed) Catalysis. Reinhold, New York, pp 109-148

4. Bond GC (2005) Metal-catalysed reactions of hydrocarbons. Springer, New York

5. Teschner D, Vass E, Hävecker M, Zafeiratos S, Schnörch P, Sauer H, Knop-Gericke A, Chamam M, Wootsch A, Canning AS, Gamman JJ, Jackson SD, McGregor J, Gladden LF, Schlögl R (2006) J Catal 242:26-37

6. Teschner D, Borsodi J, Wootsch A, Révay Z, Hävecker M, Knop-Gericke A, Jackson SD, Schlögl R (2008) Science 320(5872):86-89

7. Wilde M, Fukutani K, Ludwig W, Brandt B, Fischer J-H, Schauermann S, Freund H-J (2008) Angew Chem Int Ed 47:9289-9293

8. Zaera F (2009) Acc Chem Res 42:1152-1160

9. Lee I, Zaera F (2013) Top Catal 56:1284-1298

10. Shaw LA, Jackson SD (1996) Appl Catal A: Gen 134:91-99

11. Jackson SD, Spence RR (2007) In: Schmidt SR (ed) Catalysis of organic reactions. Taylor \& Francis, Boca Raton, pp 241-246

12. Wilhite BA, McCready MJ, Varma A (2002) Ind Eng Chem Res 41:3345-3350

13. Golubina EV, Lokteva ES, Erokhin AV, Veligzhanin AA, Zubavichus YV, Likholobov VA, Lunin VV (2016) J Catal 344:90-99

14. Wondergem CS, Hartman T, Weckhuysen BM (2019) ACS Catal 9:10794-10802

15. Jackson SD, Kelly GJ (1997) Curr Top Catal 1:47-59

16. Dobrovolna Z, Kacer P, Cerveny L (1998) J Mol Catal A: Chem 130:279-284

17. Kacer P, Cervený L (2002) Appl Catal A: Gen 229:193-216

18. Hamilton CA, Kelly GJ, Spence RR, de Bruin D, Jackson SD (2002) Appl Catal A Gen 237:201-209

19. Jackson SD, Canning AS, Monaghan A, Wright T (2006) Catal Today 116:22-29

20. Begley LC, Kakanskas KJ, Monaghan A, Jackson SD (2012) Catal Sci Technol 2:1287-1291

21. Pavel V, Markov PV, Mashkovsky IS, Bragina GO, Wärnå J, Gerasimov EY, Bukhtiyarov VI, Stakheev AY, Murzin DY (2019) Chem Eng J 358:520-530

22. Greenfield H (1973) Ann N Y Acad Sci 214:233-242

23. Alshehri F, Weinert HM, Jackson SD (2017) React Kinet Mech Cat 122:699-714

24. Canning AS, Jackson SD, Monaghan A, Spence RR, Wright T (2008) In: Prunier M (ed) Catalysis of organic reactions. Taylor \& Francis, Boca Raton, pp 99-102

25. Bond GC, Rank JS (1965) In: Sachtler WHM, Schuit GCA, Zwietering P (eds) Proceedings of the third international congress on catalysis, vol 2. North Holland, Amsterdam, pp 1125-11

26. Furukawa S, Yi P, Kunisada Y, Shimizu K-I (2019) Sci Technol Adv Mater 20:805-812

27. Shamsiev RS, Finkelshtein EI (2018) J Mol Model 24:143

28. Ali J, Jackson SD (2014) Appl Petrochem Res 4:33-39

29. Iucci G, Carravetta V, Paolucci G, Goldoni A, Russo MV, Polzonetti G (2005) Chem Phys 310:43-49

30. Sohn Y, Wei W, White JM (2007) J Phys Chem C 111:5101-5110

31. Casey NJ, Jackson SD (1993) React Kinet Catal Lett 49:231-234

32. Sohn Y, Wei W, White JM (2007) Langmuir 23:12185-12191

33. Schauermann S (2018) In: Jackson SD (ed) Hydrogenation: catalysts and processes. de Gruyter, Berlin, p 43-74

34. Gorodetskii VV, Nieuwenhuys BE, Sachtler WMH, Boreskov GK (1981) Surf Sci 108:225-234

35. Nichtl-Pecher W, Stammler W, Heinz K, Muller K (1991) Phys Rev B: Condens Matter 43:6946-6951

36. Pauer G, Eichler A, Sock M, Ramsey MG, Netzer F, Winkler A (2003) J Chem Phys 119:5253-5266

37. Christmann K (2009) Surf Sci 603:1405-1414

38. Ferrin P, Kandoi S, Nilekar AU, Mavrikakis M (2012) Surf Sci 606:679-689

Publisher's Note Springer Nature remains neutral with regard to jurisdictional claims in published maps and institutional affiliations. 